\title{
Performance of Landfill Leachate Treatment from Laterite Based Soil-Layering System: A Laboratory Scale Investigation
}

\author{
Nayanthika I.V.K.*, Jayawardana D.T., Madusanka R.M.T.D. \\ Department of Forestry \& Environmental Science, University of Sri Jayewardenepura, Sri Lanka \\ *kalaninayanthika26@gmail.com
}

\begin{abstract}
Landfill leachate is a major issue throughout the world. In the Sri Lankan scenario there are not enough methods to treat or control generated leachate. Therefore the ultimate aim of this research is to evaluate the performances of laterite soil and compost to treat landfill leachate using a cost effective and reliable technique. Several standard procedures available in literature were incorporated with this study. Five different soil-layering systems (filters) were prepared by mixing laterite soil with compost $(0 \%, 10 \%, 20 \%, 30 \%$ and $40 \%$ by weight). Leachate from the Karadiyana control dumpsite was fed for each filter over 100 days to evaluate the filtering performances of selected parameters such as BOD, COD, TSS, EC, ORP, pH, Phosphates, Nitrates and selected heavy metals including $\mathrm{Zn}, \mathrm{Ni}, \mathrm{Pb}, \mathrm{Mn}, \mathrm{Cu}, \mathrm{Fe}$ and $\mathrm{Cd}$. For each parameter, filtering efficiencies were calculated and concentrations of each parameter were compared with the selected water quality standards. In addition, KruskalWallis and Mann-Whitney non-parametric tests were used for studying filtering efficiencies of those parameters. During the experiment, $\mathrm{pH}$ of all filtering systems was within 6.0-8.5 which complies with the water quality standards. Even after 100 days of operation, filtering efficiencies of BOD (>90\%), COD (>85\%), Nitrates $(75-95 \%)$ and Phosphates $(>90 \%)$ were at higher levels. Removal efficiencies of both TSS (40-90\%) and EC (0-80\%) illustrated wide range of fluctuations. Greater filtering efficiencies were obtained for Fe (90-100\%). Highly diverse efficiencies were found for $\mathrm{Mn}, \mathrm{Cu}, \mathrm{Ni}, \mathrm{Cd}, \mathrm{Zn}$ and $\mathrm{Pb}$. Within the operational period, phosphate and nitrate concentrations were fitted to water quality standards. However, COD and BOD concentrations were fixed to those standards especially after 25 days. Abundances of $\mathrm{Cd}, \mathrm{Cu}, \mathrm{Fe}, \mathrm{Zn}$ and $\mathrm{Ni}$ were reached or very close to the maximum permissible levels of water quality standards. Conversely, TSS, $\mathrm{Mn}$ and $\mathrm{Pb}$ in the filtrates ignore the standard recommended levels. According to the statistical analysis, it can be ultimately concluded that using $20 \%$ of compost with $80 \%$ of laterite by dry weight gives the optimum conditions for the greater filtering performances.
\end{abstract}

Keywords: Leachate, Laterite, Filter

Proceedings of the $22^{\text {nd }}$ International Forestry and Environment Symposium 2017 of the Department of Forestry and Environmental Science, University of Sri Jayewardenepura, Sri Lanka 